\title{
An RCM Implementation for Wind Turbine Maintenance using MFEA Method and NHPP Model
}

\author{
Reynaldo Condori Yucra, MSc. ${ }^{1}$, Norman Beltrán Castañón, Ph.D. ${ }^{2}$, José Ramos Cutipa, MSc. ${ }^{2}$, Saul Huaquipaco \\ Encinas, Eng.. ${ }^{1}$, Rodrigo Aquino Larico, MSc. ${ }^{1}$, Henry Pizarro Viveros, Ph.D. ${ }^{1}$ and Henry Shuta Lloclla, MSc. ${ }^{2}$ \\ ${ }^{1}$ Universidad Nacional de Juliaca, Peru, reynaldo_yufra@hotmail.com, saul@pizdii.com,rodrigo19_x@hotmail.com, \\ henry_pizarro@hotmail.com \\ 2Universidad Nacional del Altiplano, Peru,normanjesus@gmail.com,joseramosc@hotmail.com,henshuter@hotmail.com
}

\begin{abstract}
The implementation of wind power plants for the generation of energy is becoming increasingly popular, however the generation equipment may have failures due to factors of the equipment or operation, in this sense it is important to have a predictive maintenance strategy that allows to anticipate the possible faults that could arise. In this paper we propose the implementation of a Reliability-Centered Maintenance (RCM) scheme, applied to a wind turbine plant using Failure Mode Effect Analysis (FMEA) and Non-Homogeneous Poisson Process (NHPP), which require minimal use of advanced monitoring technologies and simple data acquisition systems. For this, the critical components of the wind system that may present failure are used as indicators to predict the general maintenance time of the system. First, these components to be used as indicators for predictive maintenance are chosen using the FMEA method, where the most critical components are chosen. Second, the fault information of the chosen components are analyzed using the NHPP model; Finally, the analysis of the results is carried out, especially calculating the average time of failure and thus deciding the time of general maintenance of the wind system. The present work demonstrates the validity of these known techniques applied to a wind generation plant, thus supporting the development of the implementation of more wind generator centers.
\end{abstract}

Keywords-Wind Turbine maintenance, RCM, MFEA, NHPP.

\section{INTRODUCTION}

Wind energy is expected to play an increasingly important role in the future international energy scenario. Experts predict that this technology could cover $5 \%$ of the global energy market by 2020. The applications of wind energy through wind systems, both on-shore and off-shore, have been growing at a dizzying pace throughout the world. Being part of the electric generation system in the wind turbines of wind farms demands high availability that will be closely linked with reliability, operation and maintenance $(\mathrm{O} \& \mathrm{M})$.

Precisely for this reason, it is significant that each company in charge of $\mathrm{O} \& \mathrm{M}$ given as concessions present modern maintenance management programs according to the needs of this type of power generation industries, to optimize the distribution of energy connected to the network from the power plants wind, through its own system or the national interconnected electrical system (SEIN). In our country, the use of wind energy is already a reality for the diversification of the energy matrix, particularly in the coastal area that has great wind potential.

Digital Object Identifier (DOI): http://dx.doi.org/10.18687/LACCEI2018.1.1.500 ISBN: 978-0-9993443-1-6

ISSN: $2414-6390$
However, in order to achieve the increase of the participation of wind energy in the national energy matrix, it is necessary to determine the correct operation and maintenance of wind farms or large capacity wind farms (CE) [3].

That is why the development of this research article aims to present a methodology designed to determine the energy production of high power wind turbines $(>1000 \mathrm{~kW})$ increasing their availability and reliability. Specifically, the study is based on reliability (RCM) applied to a wind turbine plant using Failure Mode Effect Analysis (FMEA) and non-homogeneous Poisson process (NHPP), which require minimal use of advanced monitoring technologies. and sophisticated data acquisition systems. For this, the critical components of the wind system that may present failure are used as indicators to predict the general maintenance time of the system. First, these components to be used as indicators for predictive maintenance are chosen using the FMEA method, where the most critical components are chosen. Second, the fault information of the chosen components are analyzed using the NHPP model; Finally, the analysis of the results is carried out, especially calculating the average time of failure and thus deciding the time of general maintenance of the wind system.

The following section of the paper, Section II reviews the process of implementation of maintenance centered on reliability. Section III presents the description and analysis of the data used for experimental process. Section IV, basically demonstrates how the proposed methodology is tested. Finally, the general conclusion is presented in Section V.

\section{PROCESS OF IMPLEMENTATION OF MAINTENANCE CENTERED ON RELIABILITY}

A repairable system is a system that can be repaired when it is affected by faults, such as electric motors and compressors. A non-repairable system is a system that is discarded or replaced when it fails, such as electronic parts and bulbs. To model repairable systems, the most recommended model is the Non Homogeneous Poisson Process (NHPP) [6].

\section{A. Optimization of Maintenance Strategies}

The NHPP model considers that the failure rate varies as the system ages, specifically this model considers that when the failure occurs, the system is subjected to a basic repair; and that therefore it remains "as bad as it was", just before the event of failure. This model is valid for complex equipment,

$16^{\text {th }}$ LACCEI International Multi-Conference for Engineering, Education, and Technology: "Innovation in Education and Inclusion", 19-21 July 2018, Lima, Peru. 
with multiple components, in which, the policy of restoration (maintenance), consists of only making basic repairs (originally proposed by the manufacturer)

\section{B. Analysis of Model Failure Trend}

We can apply two methods: the graph, where the accumulated times of failures are plotted versus the number of failures in linear scale, see fig. 03; To determine if the fault data have a tendency and follow the NHPP, the Centroid or Laplace test was used. This consists of determining the parameter $U$ [6] [7], such that:

$$
U=\frac{\frac{\sum_{i=1}^{n} t_{i}}{n}-\frac{t_{0}}{2}}{t_{o \sqrt{\frac{1}{12 n}}}} \ldots \ldots \ldots \ldots \ldots \ldots \ldots
$$

variable $\mathrm{U}$, approximates a normal distribution, where:

$$
\begin{aligned}
& \text { t0: Time of observation of the failures } \\
& n: \text { Number of observed failures } \\
& \text { ti: Time between successive failures valid for } n=3 \\
& \text { If } U=0 \text {, there is no evidence of trend } \\
& \text { If } U>0 \text {, the trend is evident and growing } \\
& \text { If } U<0 \text {, the trend is evident and decreasing }
\end{aligned}
$$

\section{Non-Homogeneous Poisson Process Model}

In the non-homogeneous Poisson process, the failure rate is time-dependent. Therefore, the process is non-stationary because the failure rate is not, nor is it independent, nor is it distributed identically over time [8] [9], so:

$$
\begin{array}{r}
F\left(t_{i}\right)=1-\exp \left[\left(\frac{t_{i}-1}{\alpha}\right)^{\beta}-\left(\frac{t_{i}}{\alpha}\right)^{\beta}\right] \ldots \ldots . \\
\wedge\left(t_{n}, t_{n+s}\right)=\frac{1}{\alpha^{\beta}}\left[\left(t_{n}+t_{s}\right)^{\beta}-\left(t_{n}\right)^{\beta}\right] . \\
T N F=\left(\frac{1}{\alpha}+t_{n}^{\beta}\right)^{\frac{1}{\beta}}-t_{n}
\end{array}
$$

$\Lambda \quad$ : Total number of faults expected in the time interval [ts]

TNF: Expected time in which the next fault will occur (Reference value to design when to perform maintenance)

ts: It is the time in which you want to know the number of faults expected from the last event.

tn: Total failure times

When engineers analyze the history of a team's failures, they evaluate the total of the data without making any difference between the elements of that equipment. In the present work, the data were processed using Pareto graphics, to have the number of elements that cause failures, this process gives us a number of elements that cause the failure.

\section{DATA COLLECTION}

In this step, all the possible information is gathered regarding: operation and maintenance of wind turbines, manual installation diagrams of the component manufacturers.

The data found is shown in the background that is historical data of 11 and 8 years of studies.

The wind industry currently uses only reactive maintenance (they were left running until the failure occurred) and preventive maintenance (following the service manual of the wind turbine manufacturer) and is not yet well versed in the more recent forms of maintenance known collectively as predictive maintenance, which uses state-of-the-art technology control technologies. As the capacity of the wind turbines grew, the preventive maintenance was adapted more.

Tavner [10] conducted a study in 2007 in which he classified wind turbine faults based on batteries of wind turbine failure data collected over 11 years in 4000 machines in Germany and 1000 in Denmark [9].

On the other hand, Ribrant in 2007 [5] carried out a similar study in which it analyzed for 8 years the failures registered in Swedish; finally, Durstewitz presented a similar research in German wind farms [11]. Table 01 presents the comparative values of these three studies.

Where:

Table 01: DistriBUTION OF NUMBER OF FAILURES FOR SWEDISH WIND POWER PLANTS BETWEEN [5], [10], [11] [DURSTEWITZ, 2003] [ [TAVNER, 2007] [RIBRANT, 2007]

\begin{tabular}{lclclc}
\hline Electric System & $23 \%$ & Electric System & $23.8 \%$ & Electric System & $17.15 \%$ \\
Control System & $18 \%$ & Electronic Control & $17.9 \%$ & Control System & $12.9 \%$ \\
Sensors & $10 \%$ & Sensors & $10.4 \%$ & Sensors & $14.1 \%$ \\
Hydraulic System & $9 \%$ & Hydraulic System & $9.6 \%$ & Hydraulics & $13.3 \%$ \\
Yaw System & $8 \%$ & Yaw System & $7.5 \%$ & Yaw System & $6.7 \%$ \\
Multiply & $4 \%$ & Rotor & $7.1 \%$ & Gears & $9.8 \%$ \\
Mechanical Brakes & $6 \%$ & Mechanical Brakes & $5.4 \%$ & Mechanical Brakes & $1.2 \%$ \\
Blades/Pitch & $7 \%$ & Blades/Pitch & $11 \%$ & Blades/Pitch & $13.4 \%$ \\
\hline
\end{tabular}

16 ${ }^{\text {th }}$ LACCEI International Multi-Conference for Engineering, Education, and Technology: "Innovation in Education and Inclusion", 19-21 July 2018, Lima, Peru. 
Analyzing the information in the work of Ribrant [5], the average time of interruptions due to failures, per year, varies between 62 hours and 172 hours, that is, between 2 days and 7 days. Table 02 presents the record of annual failures registered by Rimbrant [5].

Table 02: Record of annual failures taken in this study [5]

\begin{tabular}{lrrr}
\hline Component & $\begin{array}{l}\text { Number of } \\
\text { failures per } \\
\text { year [n] }\end{array}$ & $\begin{array}{l}\text { Downtime } \\
\text { per failure } \\
\text { [hours] }\end{array}$ & \multicolumn{1}{l}{$\begin{array}{l}\text { Downtime } \\
\text { per year }\end{array}$} \\
\hline Hub & 0,11 & 85,8 & 9,5 \\
Blades/Pitch & 0,17 & 99,4 & 17,1 \\
Generator & 0,10 & 179,2 & 17,5 \\
Electric System & 0,55 & 36,4 & 20,1 \\
Control System & 0,41 & 45,8 & 18,9 \\
Drive train & 0,05 & 137,3 & 7,4 \\
Sensors & 0,24 & 35,8 & 8,7 \\
Gears & 0,10 & 153,3 & 15,6 \\
Mechanical & & & \\
Brakes & 0,13 & 64,8 & 8,5 \\
Hydraulics & 0,23 & 28,4 & 6,5 \\
Yaw System & 0,18 & 64,6 & 11,6 \\
Structure & 0,09 & 79,7 & 7,5 \\
\hline Total/Average & Tot: 2,38 & Avg: 62,6 & Tot: 149,0 \\
\hline
\end{tabular}

Table 03 shows the Pareto analysis that will serve as a reference in the design of the RCM, where combining the last two columns we plot the Pareto curve, Figure 01.

Table 03: Pareto Analysis

\begin{tabular}{rrrrrrr}
\multicolumn{7}{c}{ Table 03: Pareto Analysis } \\
\hline $\begin{array}{c}\text { Out of } \\
\text { service } \\
\text { time (Ci) }\end{array}$ & $\begin{array}{c}\text { Number of } \\
\text { fails (Fi) }\end{array}$ & \multicolumn{1}{c}{$\Sigma$ Ci } & $\Sigma \mathrm{Fi}$ & $1 / \mathrm{Ct} \Sigma \mathrm{Ci}$ & $1 / \mathrm{Ft} \Sigma \mathrm{Fi}$ \\
\hline 3 & 0.143 & 0.175 & 0.1 & 0.2 & $14 \%$ & $18 \%$ \\
6 & 0.054 & 0.141 & 0.1 & 0.1 & $5 \%$ & $14 \%$ \\
1 & 0.094 & 0.134 & 0.1 & 0.3 & $15 \%$ & $28 \%$ \\
9 & 0.044 & 0.133 & 0.2 & 0.4 & $19 \%$ & $41 \%$ \\
4 & 0.183 & 0.129 & 0.4 & 0.5 & $38 \%$ & $54 \%$ \\
7 & 0.194 & 0.098 & 0.6 & 0.6 & $57 \%$ & $64 \%$ \\
10 & 0.133 & 0.067 & 0.7 & 0.7 & $70 \%$ & $70 \%$ \\
2 & 0.089 & 0.055 & 0.8 & 0.8 & $79 \%$ & $76 \%$ \\
12 & 0.017 & 0.027 & 0.8 & 0.784 & $81 \%$ & $79 \%$ \\
11 & 0.012 & 0.015 & 0.8 & 0.799 & $82 \%$ & $80 \%$ \\
8 & 0.012 & 0.012 & 0.8 & 0.811 & $83 \%$ & $81 \%$ \\
5 & 0.024 & 0.011 & 0.9 & 0.822 & $86 \%$ & $82 \%$ \\
\hline$\Sigma$ & 1.0 & 1.0 & & & & \\
\hline \multicolumn{7}{c}{} \\
\hline
\end{tabular}

The curve is divided into three zones: A, B and C. Zone A shows that approximately $20 \%$ of the faults produce $80 \%$ of the costs; Faults in this area must be clearly prioritized. In area B, $15 \%$ of the costs are concentrated, which are produced by $30 \%$ of the faults. Zone $\mathrm{C}$ only concentrates $5 \%$ of the costs produced by $50 \%$ of the faults. These failures have the lowest solution priority.

The previous analysis considers that the failures are similar in intervention cost; in general, this can vary between failure and failure in an important way, depending on the failure modes involved.

This analysis will serve as a reference for the design of the RCM of the study to be carried out.

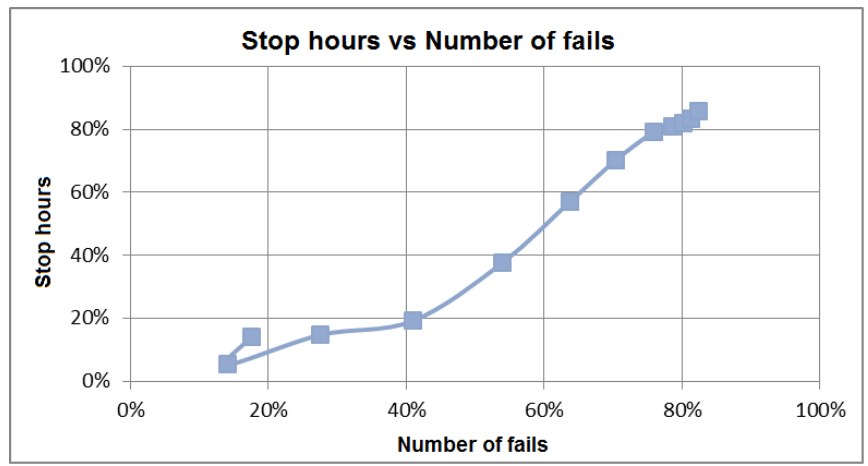

Figure 01. Pareto curve of stop hours vx number of fails

\section{DEVELOPMENT OF FAILURE MODES AND EFFECTS ANALYSIS (FMEA) OF THE WIND TURBINE}

The FMEA is a systematic method that allows identifying problems before they occur and that may affect or impact the processes and products in a given area, under a given operational context.

In FMEA conducted in this work, does not analyze the wind turbine as a whole, but enters to divide it into its subsystems that will identify in detail the components of the selected systems of only five systems according to the level of criticality shown in table 06: All these systems are equipped with sensors that allow to know the status of them.

Here are some of the defined functions of the FMEA performed in this study as an example.

\section{B. Input-Process-Output Diagram}

A wind turbine converts wind energy into electricity by a positive displacement hydraulic pump. The hydraulic pump is disposed adjacent a shaft coupled to a hub. In one embodiment, the rotation of the hub drives the hydraulic pump. In Fig. 02 is presented the main components of the system.
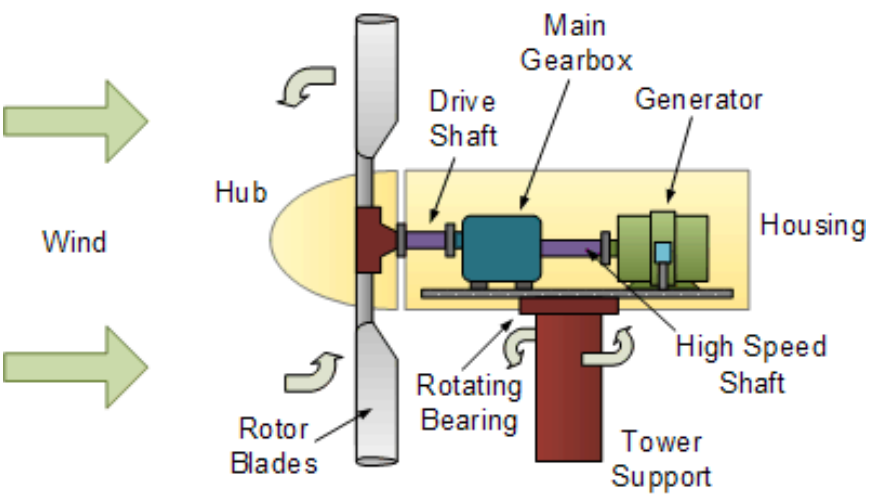

Figure 02. Wind turbine system, input-output scheme.

$16^{\text {th }}$ LACCEI International Multi-Conference for Engineering, Education, and Technology: "Innovation in Education and Inclusion", 19-21 July 2018, Lima, Peru. 


\section{B. Estimation of the Reliability of Critical Elements}

The identification of critical components allows the monitoring of their status and even for redundancy to increase reliability. The statistic defines the reliability as the probability that an element does not fail in a pre-set time interval $(0, t)$ :

$$
\begin{gathered}
\mathrm{R}(\mathrm{t})=1-\mathrm{F}(\mathrm{t})=\mathrm{P}(\mathrm{T} \geq \mathrm{t}) \ldots \ldots \ldots \ldots \ldots \ldots \\
F(t)=P(T \leq t)=\int_{0}^{\infty} f(t) \times d t=1-R(t)
\end{gathered}
$$

Where:

$F(t)$ : Fault function represented by a continuous random variable. For each value of $t, F(t)=P(T<t)$ provides the probability of element failure in that time. [2]

$f(t)$ : Failure probability density function

$$
\lambda(t)=-\frac{R^{\prime}(t)}{R(t)}=\frac{f(t)}{R(t)}
$$

Where:

$\lambda(t)$ : Fault rate is the speed at which faults occur, and each point of the fault indicates the instantaneous possibility of failure of a device that has survived up to that point ( $t$ ) [5].

Thus, by clearing $\mathrm{R}(\mathrm{t})$ and considering that $\mathrm{R}(\mathrm{t}=0)=\mathrm{R}_{0}$ an initial reliability, normally $\mathrm{R}_{0}=1$.

$$
R(t)=R_{0} e^{-\int_{0}^{t} \lambda(t) d t}
$$

We selected four critical elements of a wind turbine system in order to compute their fail rate and reliability rate. Table 4 shows the computed values.

Table 4: Reliability of the criticals elements and fails distribution.

\begin{tabular}{lllc}
\hline Item & Fail Element & Fail rate $(\lambda)$ & Reliability $(\mathrm{R})$ \\
\hline 1 & $\begin{array}{l}\text { Orientation } \\
\text { mechanism }\end{array}$ & 0.0000115 & 0.9013 \\
2 & Generator & 0.000000769 & 0.9931 \\
3 & Main Gearbox & 0.00000063 & 0.9944 \\
4 & Rotor bladess & 0.00001116 & 0.9068 \\
\hline
\end{tabular}

\section{Estimation of Model Parameters (NHPP)}

The parameter estimation using the Laplace analytical model is shown in Figure 03, which is the result of combining the cumulative time with the number of fail that occurs (Columns 3 and 1 of Table 5).

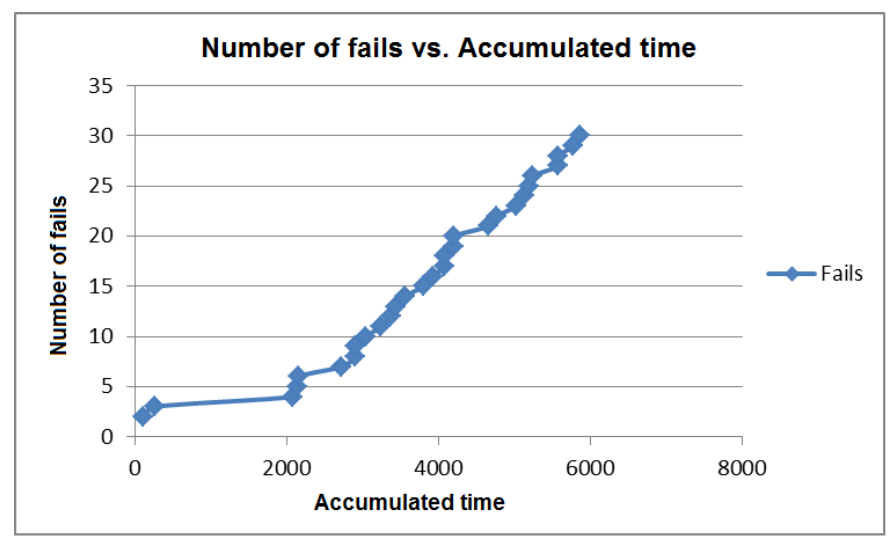

\begin{tabular}{|c|c|c|c|c|}
\hline \multirow{2}{*}{$\begin{array}{l}\text { Number } \\
\text { of fails }\end{array}$} & \multicolumn{3}{|c|}{ Cumulative } & \multirow[b]{2}{*}{$\operatorname{Ln}(\mathrm{T} / \mathrm{TI})$} \\
\hline & Time & Time & $(\mathrm{T} / \mathrm{TI})$ & \\
\hline 1 & 109 & 109 & 54.8807339 & 4.005162356 \\
\hline 2 & 149 & 258 & 23.1860465 & 3.143550654 \\
\hline 3 & 1820 & 2078 & 2.87872955 & 1.057349068 \\
\hline 4 & 67 & 2145 & 2.78881119 & 1.025615408 \\
\hline 5 & 5 & 2150 & 2.78232558 & 1.023287118 \\
\hline 6 & 573 & 2723 & 2.19684172 & 0.787020747 \\
\hline 7 & 178 & 2901 & 2.06204757 & 0.723699455 \\
\hline 8 & 7 & 2908 & 2.05708391 & 0.721289402 \\
\hline 9 & 136 & 3044 & 1.9651774 & 0.675582521 \\
\hline 10 & 196 & 3240 & 1.8462963 & 0.613181632 \\
\hline 11 & 131 & 3371 & 1.77454761 & 0.573545523 \\
\hline 12 & 71 & 3442 & 1.73794306 & 0.552702265 \\
\hline 13 & 114 & 3556 & 1.68222722 & 0.520118642 \\
\hline 14 & 247 & 3803 & 1.57296871 & 0.452964732 \\
\hline 15 & 119 & 3922 & 1.52524222 & 0.42215323 \\
\hline 16 & 161 & 4083 & 1.46509919 & 0.381922947 \\
\hline 17 & 1 & 4084 & 1.46474045 & 0.38167806 \\
\hline 18 & 116 & 4200 & 1.42428571 & 0.353670432 \\
\hline 19 & 4 & 4204 & 1.42293054 & 0.352718506 \\
\hline 20 & 448 & 4652 & 1.28589854 & 0.251457727 \\
\hline 21 & 111 & 4763 & 1.25593114 & 0.227877242 \\
\hline 22 & 263 & 5026 & 1.1902109 & 0.174130518 \\
\hline 23 & 102 & 5128 & 1.16653666 & 0.154039239 \\
\hline 24 & 68 & 5196 & 1.15127021 & 0.140865863 \\
\hline 25 & 43 & 5239 & 1.14182096 & 0.132624321 \\
\hline 26 & 334 & 5573 & 1.07338956 & 0.070821455 \\
\hline 27 & 8 & 5581 & 1.07185092 & 0.069386986 \\
\hline 28 & 187 & 5768 & 1.03710125 & 0.036429562 \\
\hline 29 & 100 & 5868 & 1.0194274 & 0.019241097 \\
\hline 30 & 114 & 5982 & 1 & 0 \\
\hline TOTAL & 5982 & 114997 & 123.1075159 & 19.04408671 \\
\hline
\end{tabular}

Figure 03: Laplace fails estimation

Table 5: Frequency of failures and accumulated time NHPP model

$16^{\text {th }}$ LACCEI International Multi-Conference for Engineering, Education, and Technology: "Innovation in Education and Inclusion”, 19-21 July 2018, Lima, Peru. 
Taking into account the statistical variable $\mathrm{U}$, we have the following analysis:

Therefore the tendency of the faults is evident and growing.

$\begin{array}{cl}\text { Total Time (TI) } & 5982 \\ \text { Acumulated Sumatory: } & 114997 \\ \text { n: } & 30 \\ \text { A } & 3833.2 \\ \text { B } & 2991\end{array}$

Laplace test U:

26714

\section{Parameters Estimation}

$$
\begin{array}{ll}
\Sigma & 19.04408671 \\
\beta: & 1575292135 \\
\alpha: & 3.30887 \mathrm{E}+05
\end{array}
$$

\section{$N^{\circ}$ of fails projected in ts hours}

$$
\begin{array}{ll}
\text { ts: } & 125 \\
\Lambda: & 0.993438
\end{array}
$$

\section{CONCLUSIONS AND RECOMMENDATIONS}

In the present work a model has been developed to develop predictive maintenance in a wind generation plant based on FMEA for the selection of components and NHPP for the determination of reliability. The present study contributes with a strategy to apply in wind power plants, which are gaining acceptance, especially in the coastal region, increasing the national energy matrix.

When obtaining a positive value for the parameter $\mathrm{U}$, it indicates that the tendency of the system is to fail over time, which validates our hypothesis, when analyzing Table 04, it is verified that in the four components described, the reliability in the model is high, above $90 \%$. On the other hand, the expected ratio of faults $(\Lambda)$ in the analyzed time interval (ts) is $99.34 \%$, this shows that the developed RCM scheme is highly reliable.

Although the methods used in the present work are widely known by the community of equipment maintenance analysis area, in the present study these concepts are updated and they are shown to be valid for their application in this type of problems oriented to predictive analysis of wind turbines.

In addition to what was mentioned in the previous paragraph, another important contribution of this work is to propose an RCM scheme to work on real data, which was published in the Rimbrant study [5], being one of the few publications that contains information on which other techniques can be applied. It should be noted that our study is the first to apply the FMEA model together with the NHPP method, using the information from Rimbrant. For us, this is very important since with it we made a contribution to the scientific community of the area and it is demonstrated that it is viable to apply our proposal for the predictive maintenance of wind turbines, especially because in our country the constitution of plants is being stimulated wind in different regions of the country.

An interesting work to develop later, is to compare the results we have obtained with other computational techniques that are in the state of the art and that are shown ad-hoc for the treatment of temporal information, such as recurrent neural networks, that not only they allow to predict the tendency, but also it could anticipate the power that a plant can generate.

\section{ACKNOWLEDGMENT}

We would like to thanks to our respective Universities for their support to develop our research specially for the implementation of the Renewable Energy Laboratory. Additionally, thanks to our colleague that review this paper.

\section{REFERENCES}

[1] EDGAR ESTUPIÑAN. "Fundamentos de las Técnicas del Mantenimiento Predictivo", Apuntes de clase, actualizado Abril del 2010, Arica, Chile.

[2] CARLOS A. PARRA MÁRQUEZ, ADOLFO CRESPO MÁRQUEZ: Ingeniería de Mantenimiento y Fiabilidad Aplicada en la Gestión de Activos, Escuela Técnica Superior de Ingenieros Industriales de la Universidad de Sevilla-España, Edita: INGEMAN, Julio - 2012.

[3] CARLOS FOLEY, Gerente de Proyectos División de Energías Alternativas, 1er Seminario: Avances en el Aprovechamiento de la Energía Eólica en el Perú y Su Potencial para la Generación de Electricidad Aislada y Conectada a la Red, Petrolera Monterrico S.A., Julio 2008.

[4] ARABIAN-HOSEYNABADI, H. AND ORAEE, H. AND TAVNER, P. J. (2010) 'Failure Modes and Effects Analysis (FMEA) for wind turbines. International journal of electrical power and energy systems. 32(7). pp. 817-824. Disponible: http://dro.dur.ac.uk/6687/1/6687.pdf

[5] J. RIBRANT: "Reliability performance and maintenance-a survey of failures in wind power systems", Master Thesis written at KTH School of Electrical, Engineering, Stockholm, Sweden, 2007.

[6] ASCHER, Harold; FEINGOLD, Harry. Repairable systems reliability: modeling, inference, misconceptions and their causes. New York: M. Dekker, 1984.

[7] CROWDER, Martin J., et al. Statistical analysis of reliability data. CRC Press, 1994.

[8] HOSSAIN, Syed A.; DAHIYA, Ram C. Estimating the parameters of a non-homogeneous Poisson-process model for software reliability. IEEE Transactions on Reliability, 1993, vol. 42, no 4, p. 604-612.

[9] GOKHALE, Swapna S., et al. Unification of finite failure nonhomogeneous Poisson process models through test coverage. En Software Reliability Engineering, 1996. Proceedings., Seventh International Symposium on. IEEE, 1996. p. 299-307.

[10]TAVNER, P. J.; XIANG, J.; SPINATO, F. Reliability analysis for wind turbines. Wind Energy, 2007, vol. 10, no 1, p. 1-18.

[11]M. Durstewitz et.al.:"Wind Energy Report Germany 2001; Annual Evaluation of WMEP”; ISET, Germany 2002 